\title{
ANALISIS SEMIOTIKA PADA IKLAN DJARUM 76 VERSI KORUPSI, PUNGLI DAN SOGOKAN
}

\author{
Nichi Hana Karlina \\ Fakultas Komunikasi dan Desain, Universitas Informatika dan Bisnis Indonesia \\ email: nichi.hana@unibi.ac.id.
}

\begin{abstract}
Abstrak
Melihat perkembangan teknologi yang pesat, berdampak pula pada bidang pertelevisian khususnya iklan televisi. Para kreator iklan televisi dituntut untuk mampu membuat iklan televisi yang menarik, diproduksi dengan teknologi canggih, bahkan beberapa iklan dibuat dengan teknik sinematografi agar dapat menyentuh perasaan audiens sehingga mampu menyampaikan makna sosial didalamnya. Seperti pada iklan Djarum 76 yang sering kali mengangkat fenomena yang terjadi di masyarakat untuk dijadikan konsep iklannya, salah satunya iklan Djarum 76 versi "korupsi, pungli dan sogokan". Dalam iklan ini diceritakan seorang warga masyarakat yang datang ke kantor pelayanan publik untuk mengurus suatu hal dan meminta untuk dilayani oleh aparat pemerintahan. Namun oknum aparat pemerintahan tersebut memungut pungli dan menawarkan diri untuk disogok oleh warga tersebut. Adegan-adegan tersebut disampaikan melalui tanda-tanda yang maknanya harus diungkap.

Tujuan dari penelitian ini adalah untuk mengungkap makna tanda, agar dapat mengetahui makna kritik sosial yang terdapat pada iklan iklan Djarum 76 versi "korupsi, pungli dan sogokan". Metode yang digunakan pada penelitian ini adalah interpretatif, peneliti akan menginterpretasi objek yang diteliti berlandaskan pendekatan Peircean Semiotics untuk menganalisis tanda. Teknik pengumpulan data dilakukan dengan cara merekam gambar dan mencatat jalan cerita pada iklan Djarum 76. Data kemudian diklasifikasikan dan dianalisis sesuai dengan makna tanda berdasarkan pendekatan Peircean Semiotics.

Hasil dari penelitian ini dapat disimpulkan bahwa iklan rokok Djarum 76 versi "korupsi, pungli dan sogokan", mengandung makna kritik sosial untuk para oknum aparat pemerintahan yang bekerja di kontor pelayanan publik, yang disampaikan dalam bentuk sindiran/satire. Iklan ini memiliki makna yang serius dan mendalam, namun dengan pengemasannya yang kental akan budaya dan mitos serta ideologi disampaikan dengan gaya parodi, iklan ini menjadi terasa lebih ringan dan menarik untuk dilihat.
\end{abstract}

\section{Kata Kunci : Semiotika, iklan, Djarum 76, korupsi.}

\begin{abstract}
Seeing rapid technological developments, has an impact on the field of television, especially television advertising. The creators of television advertising are required to be able to make attractive television advertisements, produced with advanced technology, even some advertisements are made with cinematographic techniques in order to be able to touch the audience's feelings so as to be able to convey the social meaning in it. As in the Djarum 76 advertisement which often raises phenomena that occur in the community to be used as advertising concepts, one of them is the Djarum 76 advertisement version of "corruption,
\end{abstract}


Volume 02 No. 01, April 2019

extortion and bribery". In this advertisement, a community member came to the public service office to take care of something and asked to be served by government officials. However, some government officials picked up extortion and offered to be bribed by the residents. The scenes are conveyed through signs whose meaning must be revealed.

The purpose of this research is to reveal the meaning of the sign, so that it can find out the meaning of social criticism found in the Djarum 76 advertisement advertisement for the version of "corruption, extortion and bribery". The method used in this study is interpretative, researcher will interpret the object under study based on the Peircean Semiotics approach to analyze signs. Data collection techniques are done by recording images and recording the storyline on Djarum 76 ads. Data is then classified and analyzed according to the sign meaning based on the Peircean Semiotics approach.

The results of this study can be concluded that the Djarum 76 cigarette advertisement version of "corruption, extortion and bribery", implies social criticism for government officials who work in the context of public services, which are conveyed in the form of satire. This advertisement has a serious and deep meaning, but with its thick packaging of culture and myths and ideology delivered in a parody style, this advertisement becomes lighter and interesting to look at.

Keywords: Semiotics, ads, Djarum 76, corruption. 


\section{PENDAHULUAN}

Pada perkembangan teknologi yang pesat yang mempengaruhi segala bidang, berdampak pula pada bidang pertelevisian khususnya iklan televisi. Para kreator iklan televisi dituntut untuk mampu membuat iklan televisi yang menarik, diproduksi dengan teknologi canggih, bahkan beberapa iklan dibuat dengan teknik sinematografi agar dapat menyentuh perasaan audiens sehingga mampu menyampaikan makna sosial didalamnya.

Seperti pada iklan rokok Djarum 76 yang sering kali mengangkat fenomena yang terjadi di masyarakat, seperti fenomena praktek korupsi, pungli dan sogokan sudah sering terjadi dan dapat ditemui dengan mudah dalam berbagai kesempatan dan waktu bahkan dilakukan secara terbuka, praktek ilegal tersebut sudah dianggap wajar ketika kita akan mengurus sesuatu seolah-olah sudah menjadi tradisi di Indonesia. Dalam iklan Djarum 76 versi "korupsi, pungli dan sogokan" yang diproduksi tahun 2013, diceritakan seorang warga masyarakat yang datang ke kantor pelayanan publik untuk mengurus suatu hal dan meminta untuk dilayani oleh aparat pemerintahan. Namun oknum aparat pemerintahan tersebut memungut pungli dan menawarkan diri untuk disogok oleh warga tersebut.

Tujuan dari penelitian ini adalah untuk mengungkap makna tanda, agar dapat mengetahui makna kritik sosial yang terdapat pada iklan iklan Djarum 76 versi "korupsi, pungli dan sogokan".

Iklan ini memiliki makna yang serius dan mendalam, namun dengan pengemasannya yang kental akan budaya dan mitos serta ideologi disampaikan dengan gaya parodi, iklan ini menjadi terasa lebih ringan dan menarik untuk dilihat. Adegan-adegan ditampilkan melalui tanda-tanda seperti ekspresi, body language, intonasi, dan tandatanda yang berkaitan dengan budaya, mitos serta ideologi yang maknanya harus diungkap agar dapat memahami pesan yang ingin disampaikan oleh iklan Djarum 76.

\section{METODOLOGI PENELITIAN}

Untuk mengungkap makna tanda pada iklan ini, menggunakan pendekatan Peircean Semiotics. Tanda-tanda yang merepresentasikan sesuatu akan diklasifikasikan kedalam jenis ikon, indeks ataupun simbol, kemudian tanda tersebut diinterprestasi kedalam sebuah makna. Metode yang digunakan pada penelitian ini adalah interpretatif, peneliti akan menginterpretasi objek yang diteliti berlandaskan pendekatan Peircean Semiotics untuk menganalisis tanda. Unsurunsur yang akan dianalisis adalah audio, visual, teknik pengambilan gambar (shot), dan angle. Teknik pengumpulan data dilakukan dengan cara merekam gambar dan mencatat jalan cerita pada iklan Djarum 76 versi "korupsi, pungli dan sogokan" yang diproduksi tahun 2013.

\section{HASIL DAN PEMBAHASAN}

Tema korupsi, pungli dan sogokan merupakan tema yang 'sensitif', namun iklan Djarum 76 mampu menyampaikan tema tersebut dengan cara yang menarik. Iklan dikemas dan disampaikan melalui pendekatan humor berupa sindiran, sehingga tema praktek korupsi, pungli, sogokan yang seharusnya menjadi hal yang serius dan tidak menyenangkan, dapat terasa lebih ringan, unik dan menarik untuk dilihat sehingga pesan yang ingin disampaikan dapat diterima dengan baik oleh pemirsa, selain itu pemirsa juga dapat dipengaruhi tanpa merasa, karena ada unsur senang. Humor dapat mengungkapkan pesan dengan sudut pandang yang baru. Pendekatan humor lebih rileks, dan menyenangkan (memberi hiburan pada pelihatnya).

Penyampaian tampilan tokoh-tokoh dalam iklan ini juga menggunakan teknik retorika visual (visual rethorisc) dimana penggunaan citra visual (visual images) untuk mengkomunikasikan makna. Dengan cara retorika visual ini budaya dan makna dapat direfleksikan, dikomunikasikan dan diubah oleh citra. Melalui retorika diharapkan dihasilkan efek kognitif (percaya, yakin) dan afektif tertentu (senang, 
tergugah, takut, bersemangat). Tokoh utama dalam iklan ini adalah sesosok jin lampu ajaib yang mampu mengabulkan segala permintaan ketika ada seorang manusia yang mampu mengeluarkan dia dari lampu ajaib. Dongeng jin lampu diadopsi dari dongeng 1001 malam dari kisah Aladin yang berasal dari negeri dongeng. Pada iklan ini negara Indonesia diumpamakam sebagai negeri dongeng. Sosok jin yang biasanya ditampilkan berupa wujud yang besar, menyeramkan dan berkepala gundul; pada iklan ini mengalami retorika visual dengan pendekatan metafora dimana segala bentuk perumpamaan atau kiasan disampaikan secara similarity: iconicity, analogi, likeness berupa sosok seorang pria berpakaian adat dengan logat, bahasa dan tata karma yang identik/khas dengan orang Jawa Tengah.

Cara menyampaikan sebuah realitas dalam iklan ini menggunakan teknik representasi dimana realitas tidak dapat dihadirkan, digunakan mediasi untuk 'menghadirkan realitas' itu dalam suatu bentuk, citra yang terlihat. Representasi menggantungkan diri pada dunia realitas yang mendahuluinya, agar representasi dapat berlangsung. Representasi sebagai 'reproduksi'; 'reproduksi mekanik' (seperti kamera) dapat mereproduksi sebuah realitas atau produk yang sudah ada. Salah satu representasi yang ditampilkan adalah representasi sosok Gayus Tambunan yang mewakili gambaran oknum pegawai di kantor pelayanan publik yang menjalankan praktek korupsi. Gayus Tambunan adalah seorang Pegawai Negeri Sipil yang bekerja di Ditjen pajak yang terkena kasus korupsi. Sosok Gayus Tambunan dipilih untuk mewakili oknum pegawai di kantor pelayanan publik karena kasus Gayus Tambunan cukup fenomenal dan sedang menjadi perbincangan yang hangat saat itu, sehingga sangat mudah dikenali sosok sekaligus kasusnya.

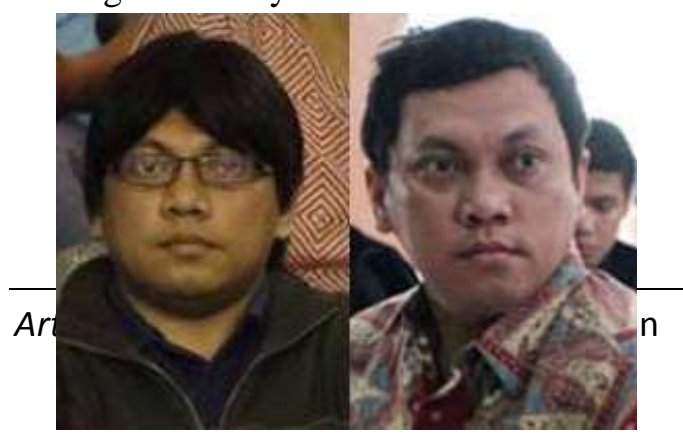

Gambar 1. Foto Gayus Tambunan (Asli)

Sumber : www.kompas.com, 14 Februari 2011

Di dalam iklan rokok Djarum 76 ini terdapat tanda-tanda yang membentuk suatu sistem tanda yang menghasilkan suatu makna. Dalam pembahasan ini tanda-tanda di uraikan berdasarkan sequence/adegan berurutan dari awal hingga akhir iklan.

\section{a. Awan Putih (real atau bukan ilustrasi} freehand) dan jingle Djarum 76

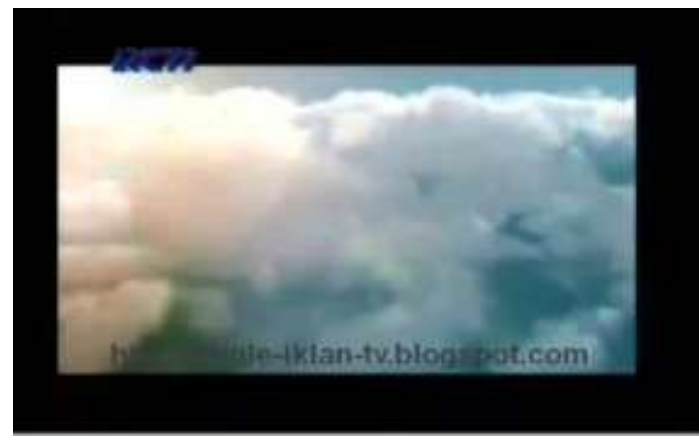

Gambar 2. Adegan 1 iklan Djarum 76 detik ke 00:00:00:01

Sumber: http://jingle-iklan-tv-blogspot.com

Pada sebuah cerita dongeng atau legenda, cerita biasanya diawali dengan kata-kata "Pada suatu hari...", dalam iklan Djarum 76 ini kata "Pada suatu hari..." (Representamen) di visualisakan dengan awan putih yang bergerak tenang (Object), makna yang sama dengan "Pada suatu hari..." yang ingin disampaikan oleh sender. Awan yang berwarna putih yang berperan sebagai helper yang membantu memberitahukan pada receiver bahwa cerita ini adalah cerita dongeng (interpretant). Namun terdapat tanda lain yaitu awan putih yang divisualisasikan dalam adegan ini adalah awan yang real atau bukan awan ilustrasi freehand yang menunjukkan bahwa cerita yang ingin disampaikan sender ini adalah cerita nyata (real) atau cerita yang benar terjadi di dunia 
nyata. Adegan diiringi oleh jingle Djarum 76 yang khas yaitu '76 (Tujuh enaaaam)". Hal ini mendakan suatu identitas bahwa iklan ini merupakan milik Djarum 76 karena setiap iklan televisi yang dibuat selalu menggunakan jingle tersebut, Djarum 76 berperan sebagai sender yaitu pengirim pesan yang disampaikan dalam sebuah cerita.

Bagan 1. Cara Membaca tanda pada Adegan 1 iklan Djarum 76

\section{b. Setting Interior dan Exterior}

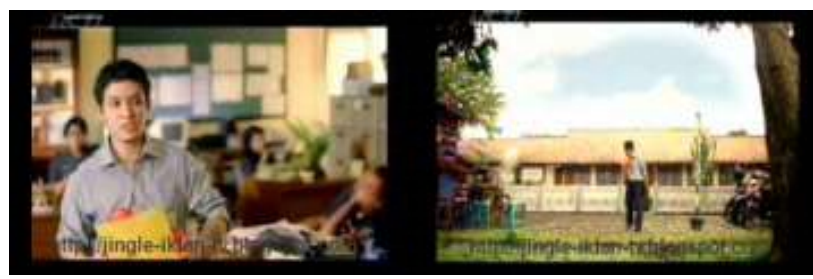

Gambar 3. Adegan iklan Djarum 76 detik ke- 00:02-00:09

Setting interior dan eksterior yang ditampilkan pada adegan di atas terdapat objek-objek yang membentuk suatu sistem tanda diantaranya tumpukan buku dan kertas, meja kerja dengan kursi yang terdapat diantara dua sisi meja yang diletakkan berhadapan, cap/stempel, mesin ketik, lemari loker berkas dan rak buku, papan informasi, pegawai/karwayan di asing-masing meja kerja, dan tampilan bangunan dari luar/eksterior. Dari objek-objek tersebut menunjukkan bahwa adegan terjadi di dalam sebuah kantor yang mengurus masalah publik.

\section{c. Aktor dan Figure}

- Aktor : Laki-laki berusia \pm 25 tahun, dengan postur tubuh tegap, proporsi tinggi dan berat badan ideal, menggunakan kemeja lengan panjang yang digulung setengah lengan, menggunakan celana panjang berbahan kain, sepatu resmi, rambut pendek disisir rapi dan membawa amplop berkas. Bersikap aktif, ekspresif dan di setiap adegan aktor 1 ini selalu muncul.. Dari ciri-ciri tersebut di atas menunjukkan bahwa aktor 1 adalah aktor utama yang sedang beraktifitas mengurus sesuatu di kantor urusan publik.



Gambar 4. Aktor 1 : Warga

(Laki-laki berusia \pm 25 tahun)

- Aktor 2 : Laki-laki berusia \pm 35 tahun, perwajahan sangat mirip dengan Gayus Tambunan yaitu seorang pegawai pajak yang terlibat kasus korupsi/mafia pajak, kasus Gayus Tambunan sangat fenomenal sehingga segala hal-hal yang berkaitan dengan masalah korupsi pada saat ini selalu dikaitkan dengan Gayus Tambunan. Gayus Tambunan $\rightarrow$ Korupsi. Pada iklan ini figure Gayus Tambunan ditampilkan namun diperankan oleh seorang Laki-laki yang secara perwajahan serta gayanya dibuat agar mirip Gayus Tambunan.

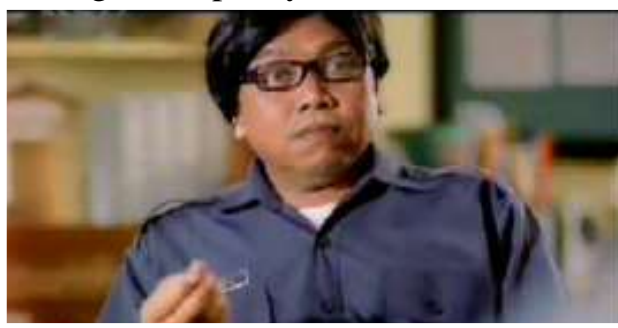

Gambar 5. Aktor 2 : Pemeran Gayus Tambunan (Petugas Kantor Pelayanan publik)

Sehingga dapat dimaknai bahwa aktor 2 ini adalah seorang pegawai kantor urusan publik yang juga menjalankan praktek korupsi seperti Gayus Tambunan.

- Aktor 3 : Aktor 3 merupakan aktor yang selalu ada dalam setiap iklan Djarum 76 versi jin lampu ajaib. Penggambaran Jin lampu ajaib pada iklan ini di representasikan oleh seorang pria dewasa berusia \pm 50 tahun 
dengan postur tinggi besar. Berdasarkan mitos dan cerita dongeng Aladin dan lampu ajaib, jin yang keluar dari lampu ajaib tersebut dapat mengabulkan segala permintaan (1-3 permintaan) orang yang mengeluarkan jin dari lampu ajaib. Jin dalam dongeng Aladin berasal dari Negara Persia. Namun sosok jin pada iklan Djarum 76 ini Jin ini selalu menggunakan baju adat Jawa Tengah yang menandakan asal perusahaan rokok Djarum 76 yaitu dari daerah Kudus, Jawa Tengah.

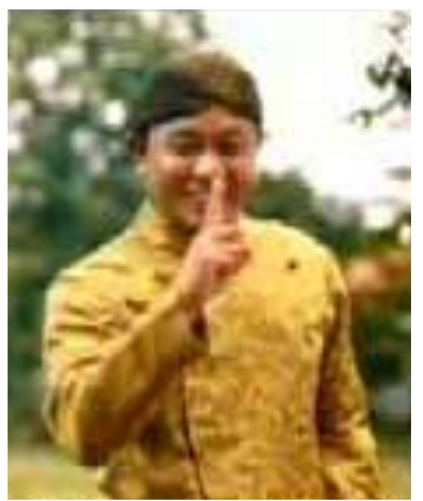

Gambar 6. Aktor 3 : Jin Lampu Ajaib

Baju yang dikenakan sesuai dengan warna identitas rook Darum 76 yaitu kuning keemasan. Bahasa dan logat jin ini pun mengguanakan bahasa Jawa. Jin ini memang selalu menghormati tuannya, namun terkadang tingkahnya tidak sesuai dengan apa yang tuannya harapkan. Sosok jin yang khas inilah yang merubah pandangan bahwa jin selalu menuruti perintah menjadi jin yang selalu bernegosiasi.

- Aktor Pendukung : Aktor pendukung ini terdiri dari 1 orang wanita dan 1 orang laki-laki, penampakan sosok mereka tidak jelas (Blur), aktor ini hanya terdapat pada adegan yang terjadi di dalam ruang kantor, menandakan bahwa meraka hanyalah aktor pendukung yang melengkapi suatu suasana aktivitas tertentu. Meskipun digambarkan tidak jelas (blur) namun gestur para aktor pendukung masih dapat dipahami.

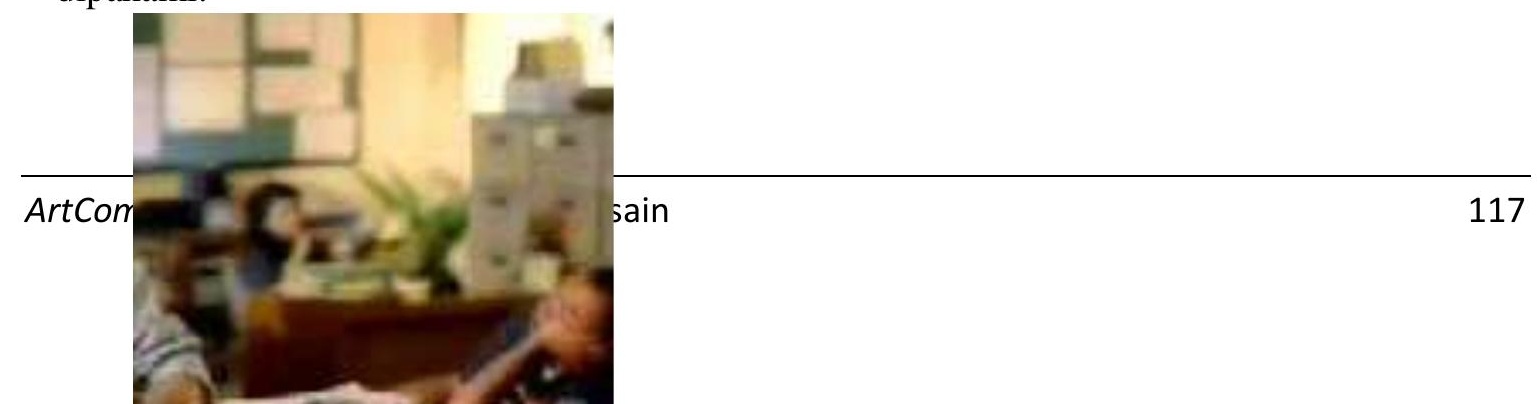

Gambar 7. Aktor pendukung (Petugas lainnya di kantor pelayanan publik)

\section{d. Bahasa Tubuh (Body Language)}

Bahasa Tubuh (Body Language) merupakan komunikasi yang (umumnya) tidak disadari. Menunjukkan internal reality seseorang, yang 'keluar' mendahului bahasa verbal. Sangat berpengaruh dan perlu dioptimalkan sesuai tujuan komunikasi. Jika berlawanan dengan bahasa verbal, akan mengurangi kekuatan komunikasi. Jika selaras dengan bahasa verbal, akan menambah kekuatan komunikasi.

Tabel 1. Body Language dan Maknanya

\section{- Analisis Adegan 1}




\section{Dari ciri-ciri body language yang} diperlihatkan aktor 1 (tersenyum) menandakan bahwa aktor 1 sedang dalam keadaan senang dan merasa nyaman sehingga membiarkan dirinya untuk membuka personal spacenya.

\begin{tabular}{|c|c|c|}
\hline No & Body Language & Menandakan \\
\hline 1 & $\begin{array}{l}\text { Personal } \\
\text { Space/Jarak } \\
\text { Berdiri Antara } 2 \\
\text { orang }\end{array}$ & $\begin{array}{l}\text { Wilayah geografis yang } \\
\text { dipersepsikan sebagai } \\
\text { teritori pribadi. Jarak yang } \\
\text { menunjukkan jauh dekatnya } \\
\text { suatu hubungan antara } 2 \\
\text { orang }\end{array}$ \\
\hline 2 & Senyum & $\begin{array}{l}\text { Perasaan orang sedang } \\
\text { senang hati, nyaman, } \\
\text { setuju. }\end{array}$ \\
\hline 3 & Ekspresi muka & Kondisi pikiran seseorang \\
\hline 4 & Open Posture & $\begin{array}{l}\text { Seseorang merasa terbuka, } \\
\text { percaya diri }\end{array}$ \\
\hline 5 & $\begin{array}{l}\text { Forward Lean } \\
\text { (Tubuh condong } \\
\text { ke depan ke arah } \\
\text { lawan bicara) }\end{array}$ & $\begin{array}{l}\text { Lawan bicara tertarik pada } \\
\text { pembicaraan kita. }\end{array}$ \\
\hline 6 & Touch & Orang merasa mulai akrab. \\
\hline 7 & $\begin{array}{l}\text { Eye Contact (soft } \\
\text { and warm) }\end{array}$ & $\begin{array}{l}\text { Keterbukaan, apa adanya, } \\
\text { terus terang }\end{array}$ \\
\hline 8 & Anggukan kepala & $\begin{array}{l}\text { Persetujuan, afirmasi, } \\
\text { akrab, suka. Terkecuali } \\
\text { orang India. }\end{array}$ \\
\hline 9 & $\begin{array}{l}\text { Meletakkan } \\
\text { tangan seperti } \\
\text { bertopang } \\
\text { dagu/menelpon } \\
\text { dengan kepala } \\
\text { dan badan } \\
\text { tegak }\end{array}$ & $\begin{array}{l}\text { Kondisi seseorang sedang } \\
\text { menganalisa/menimbang } \\
\text { pembicaraan } \\
\text { orang lain. }\end{array}$ \\
\hline 10 & $\begin{array}{l}\text { Mengangkat satu } \\
\text { kaki dan kedua } \\
\text { tangan di } \\
\text { belakang kepala }\end{array}$ & $\begin{array}{l}\text { Seseorang tengah merasa } \\
\text { dominan, menantang, } \\
\text { berkuasa. }\end{array}$ \\
\hline 11 & $\begin{array}{l}\text { Menggaruk } \\
\text { belakang } \\
\text { kepala/leher }\end{array}$ & $\begin{array}{l}\text { Kesan bohong/ragu. Kesan } \\
\text { lebih kuat jika muka } \\
\text { dialihkan dari lawan bicara. }\end{array}$ \\
\hline 12 & $\begin{array}{l}\text { Menjulurkan } \\
\text { tangan kepada } \\
\text { lawan bicara } \\
\text { dengan telapak } \\
\text { tangan di atas }\end{array}$ & Kesan jujur, terus terang \\
\hline 13 & $\begin{array}{l}\text { Memukul tubuh } \\
\text { sendiri (kepala, } \\
\text { dahi atau paha) }\end{array}$ & $\begin{array}{l}\text { Sedang kelupaan atau } \\
\text { menyalahkan diri sendiri. }\end{array}$ \\
\hline 14 & $\begin{array}{l}\text { Tangan } \\
\text { membentuk } \\
\text { Piramid }\end{array}$ & $\begin{array}{l}\text { Menandakan : Sikap } \\
\text { percaya diri, punya } \\
\text { pendapat yang diyakini. }\end{array}$ \\
\hline 15 & $\begin{array}{l}\text { Menguasai } \\
\text { Gerakan Tangan } \\
\text { (menggambarkan } \\
\text { sesuai dengan } \\
\text { perkataan) }\end{array}$ & $\begin{array}{l}\text { Gerakan jari-jari tangan } \\
\text { menadakan uang/fulus }\end{array}$ \\
\hline
\end{tabular}

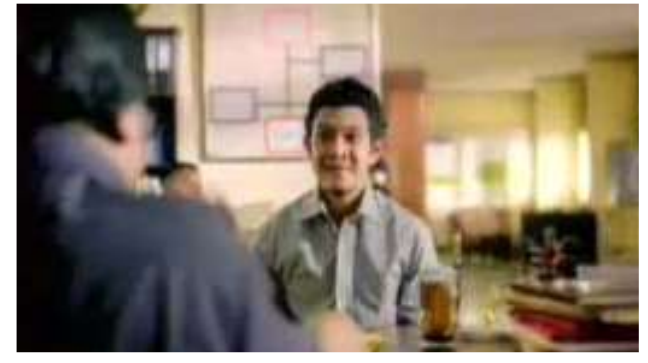

Gambar 8. Adegan 2 - Aktor 1 (Senyum)

\section{- Analisis Adegan 3}

Berdasarkan tanda-tanda yang dilakukan oleh aktor 2 (pemeran Gayus Tambunan) diantaranya; ekspresi muka yang datar dan santai, tatapan mata yang dingin, juluran tangan disertai gerakan tangan yang menandakan uang, sehingga dapat disimpulkan bahwa aktor 2 memikirkan uang dan uang yang dimaksud adalah uang sogokan atau suapan yang di minta dari lawan bicaranya secara terbuka.

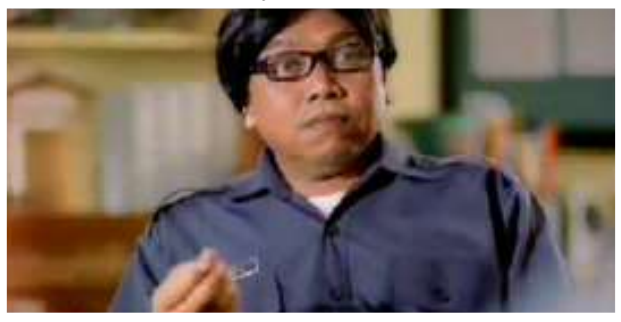

Gambar 9. Adegan 3 - Aktor 2 (Menguasai Gerakan Tangan-Gerakan jari-jati tangan menandakan uang/fulus)

\section{e. Intonasi}

Intonasi diperlukan untuk membuat pembicaraan menjadi menarik. Berbicara tanpa intonasi akan mengesankan bahwa pembicara sendiri tidak tertarik.

Tabel 2. Manfaat lain dari Intonasi

\begin{tabular}{|c|l|l|}
\hline No. & Intonasi & \multicolumn{1}{c|}{ Manfaat } \\
\hline 1. & Nada & $\begin{array}{l}\text { - Untuk mendapatkan } \\
\text { perhatian dengan cara } \\
\text { nada diturunkan } \\
\text { - Untuk menekankan kata } \\
\text { penting dengan cara nada } \\
\text { diturunkan }\end{array}$ \\
\hline 2 & Tempo & $\begin{array}{l}\text { Untuk menekankan suatu } \\
\text { kata yang kita harapkan } \\
\text { masuk ke bawah sadar. }\end{array}$ \\
\hline 3 & Timbre & $\begin{array}{l}\text { - Untuk membuat kata } \\
\text { terkesan lebih mantap }\end{array}$ \\
\hline
\end{tabular}




\begin{tabular}{|c|c|c|}
\hline & & $\begin{array}{l}\text { perberat tekanan kata } \\
-\end{array}$ \\
& & $\begin{array}{l}\text { Untuk membuat kata } \\
\text { terkesan lebih enteng } \\
\text { ringankan tekanan kata }\end{array}$ \\
\hline 4 & Jeda & $\begin{array}{l}\text { - Untuk memancing } \\
\text { munculnya rasa ingin } \\
\end{array}$ \\
& & $\begin{array}{l}\text { tahu } \\
\text { - Untuk menimbulkan } \\
\text { harapan (expectation) }\end{array}$ \\
& & \\
\end{tabular}

\section{- Analisis Adegan 4}

Ekspresi yang ditunjukkan oleh aktor 1 menunjukkan suatu kemarahan atau kejengkelan yang diakibatkan oleh adegan ke-2 yaitu adanya praktek korupsi, yang tidak sama dengan ideologinya yaitu kejujuran.

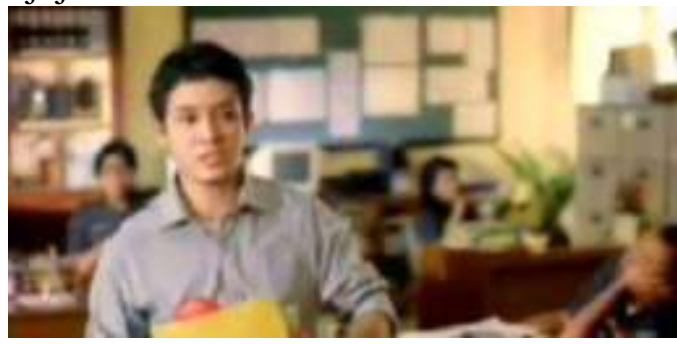

Gambar 10. Adegan 4 - Aktor 2

(Menguasai Gerakan Tangan)

Kemarahan tidak hanya ditunjukkan dengan ekspresi muka, namun didukung pula oleh kalimat yang di ucapkannya yaitu "Dasar rampok!!!” yang diucapkan dengan intonasi nada tinggi dan timbre yang berat.

\section{- Analisis Adegan 5-7}

Dalam adegan 6 aktor 1 bergegas pergi meninggalkan kantor urusan publik tersebut dengan kesal, yang ditunjukkan dengan ekspresi wajah dan langkah kaki yang cepat dan ringan. Kemudian secara tidak sengaja aktor 1 menendang sebuah lampu ajaib yang kemudian mengeluarkan asap dan muncul sesuatu yaitu jin lampu ajaib.

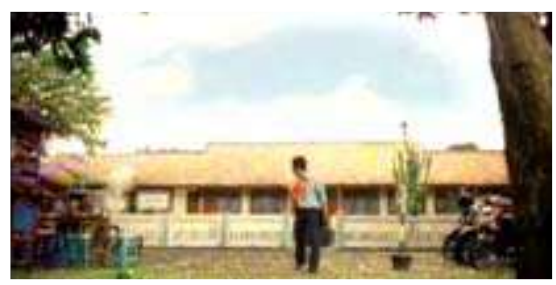

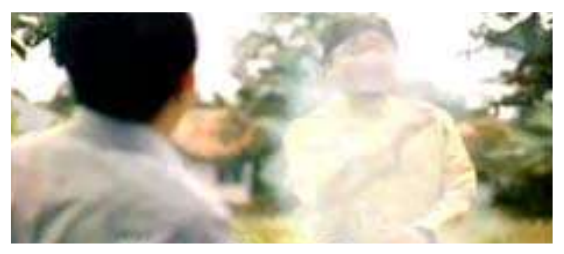

Gambar 11. Adegan 5-7. Munculnya jin dari lampu ajaib

Terdapat makna yang disampaikan dari visualisasi adegan ke-7. Biasanya lampu ajaib harus digosok-gosok agar agar jin yang terdapat di dalamnya keluar namun dalam iklan ini lampu ajaib tertendang, kemudian asap keluar dan muncul sosok jin lampu.

Tanda khusus kemunculan dari jin lampu ajaib adalah keluarnya asap, begitu pula dengan ciri khusus dari sebatang rokok, untuk mengkonsumsi rokok perlu dipantik terlebih dahulu oleh api lalu asap akan muncul, terlebih lagi ketika asap rokok dikeluarkan dari mulut pengkonsumsi, asap rokok akan keluar lebih banyak. Dari tanda tersebut jin lampu ajaib rokok direpresentasikan oleh jin lampu ajaib.

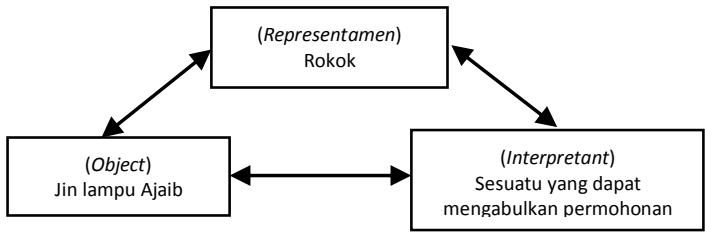

Bagan 2. Cara membaca tanda adegan 5-7

Asap yang keuar dari lampu ajaib dapat mewakili simbol dari sebatang rokok yang telah disunut oleh api. lampu ajaib dan jin yang mampu mengabulkan permintaan tuannya disejajarkan dengan rokok, diperkuat dengan penanda 'asap' dalam artian dengan mengkonsumsi rokok Djarum 76 yang dapat diperoleh di mana saja dengan mudah dapat menyelesaikan masalah dan dapat meredakan emosi.

\section{- Analisis Adegan 8}


Dalam adegan ini aktor 1 terkejut akan kehadiran sosok jin yang tiba-tiba muncul dihadapannya. Sedangkan jin langsung mengucapkan kata-kata "Ku beri satu permintaan. Monggooo..." Jin menggunakan nada yang meyakinkan bahwa permintaan aktor 1 akan terkabul. Kemudian di selang jeda yang singkat dan dilanjutkan dengan kata monggo...(bahasa Jawa) yang artinya silahkan, dilengkapi dengan bahasa tubuh dengan menggerakkan tangan (jempol yang di sodorkan yang artinya menunjukkan secara sopan) ke hadapan lawan bicara, menandakan bahwa jin menghormati tuannya.

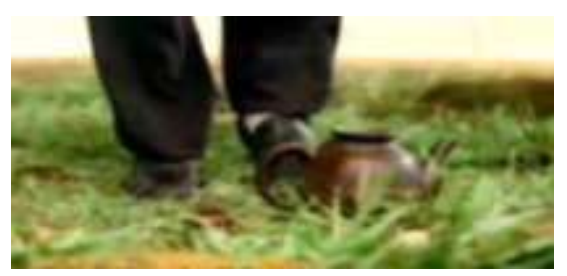

$$
\begin{gathered}
\text { Gambar 12. Adegan 8. Jin lampu ajaib } \\
\text { menawarkan kepaa tuannya untuk } \\
\text { mengajuan satu permohonan }
\end{gathered}
$$

\section{- Analisis Adegan 9}

Adegan 9, aktor 1 menyampaikan permintaanya yaitu "mau korupsi, pungli, songkan, hilang dari muka bumi , bisa jin?" aktor mengucapkan dengan ekspresi yang bersemangat, menggebu-gebu, dengan intonasi nada yang tinggi. Namun jin menjawab "bisa diatur.....wani piro?" pada jawaban tersebut jin mulai memainkan intonasinya awalnya meyakinkan bahwa dia bisa, tapi di akhir kalimat dia mengajukan negosiasi dengan kalimat wani piro? (bahasa Jawa yang artinya berani berapa), yang berarti jin ini pun menawarkan praktek korupsi, dan mewarkan dirinya untuk di suap.

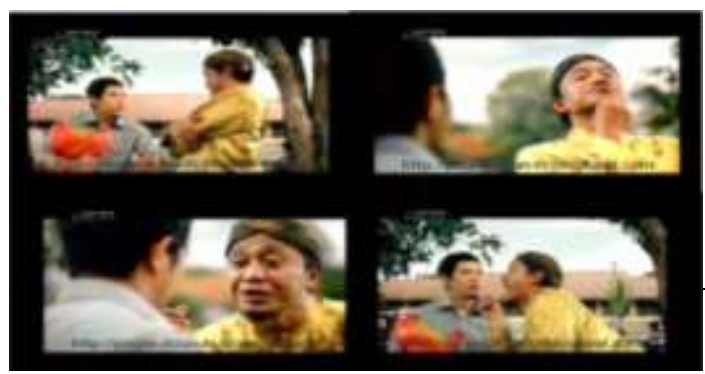

Gambar 13. Adegan 9. Aktor 1 menyampaikan permintaanya, tapi jin mengajukan negosiasi dengan kalimat wani piro?

\section{- Analisis Adegan 10-12}

Adegan ini adalah adegan penutup iklan Djarum 76 versi korupsi, pungli dan sogokan. Diakhiri dengan adegan 10-12, awan cerah namun dibuat dengan ilustrasi freehand, dengan ilustrasi freehand ini menandakan makna yang berbeda dengan awan real yang terdapat pada adegan 1 .
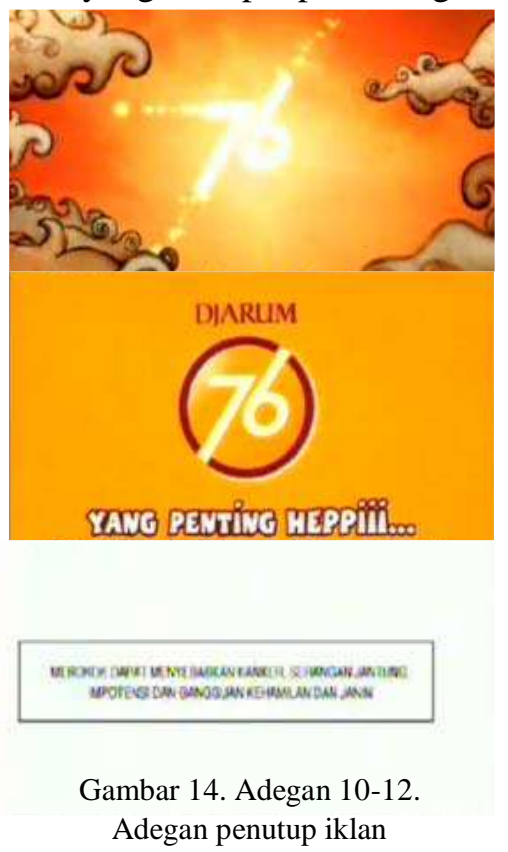

Kejadian nyata tersebut memang sangat menguras emosi namun oleh sender dibuat dengan memadukan dunia nyata dan dongeng agar menjadi parodi yang menarik, lucu namun pemirsa masih dapat mengambil maknanya bahwa pada saat ini kejujuran seolah-olah sudah tidak ada lagi, ditandai dengan sikap jin yang sudah berani bernegosiasi. Djarum 76 ingin menunujukkan arti penting tersebut, namun agar suasana menjadi cair kembali Djarum 
76 menampilkan dan menyebutkan tageline "yang penting heppiii..." dengan intonasi

menghibur, menyenangkan dan memainkan, didukung juga oleh pemilihan font (jenis huruf) yang dinamis, kekeluargaan dan santai.

\section{KESIMPULAN}

Hasil dari penelitian ini dapat disimpulkan bahwa iklan rokok Djarum 76 versi "korupsi, pungli dan sogokan", mengandung makna kritik sosial untuk para oknum aparat pemerintahan yang bekerja di kontor pelayanan publik, yang disampaikan dalam bentuk sindiran/satire. Prosedur pengurusan administrasi di kantor pelayanan publik seharusnya bebas biaya apapun, karena aparat telah di gaji oleh pemerintah, namun yang terjadi di lapangan, prosedur-prosedur tersebut sering kali dijadikan lahan untuk praktek korupsi, pungli dan sogokan. Selain terdapat makna sosial, iklan ini juga merupakan suatu strategi penjualan produk Djarum 76. Rokok disimbolisasikan melalui sosok jin lampu ajaib yang dapat mengabulkan permintaan tuannya yang telah membebaskannya, sehingga dapat diartikan bahwa merokok dapat memudahkan/melancarkan segala urusan. Tayangan iklan ini secara tidak langsung mempersuasi konsumen untuk membeli produk rokok tersebut. Iklan ini memiliki makna yang serius dan mendalam, namun dengan pengemasannya yang kental akan budaya dan mitos serta ideologi disampaikan dengan gaya parodi, iklan ini menjadi terasa lebih ringan dan menarik untuk dilihat.

\section{REFERENSI}

Danesi, Marcel. (2010). Pengantar Memahami Semiotika Media.

Yogyakarta : Jalasutra.

Eco, Umberto. (2009). Teori Semiotika. Yogyakarta : Kreasi Wacana Yogyakarta.
Nort, Winfried (1995). Handbook Of Semiotics. Bloomington : Indiana University Press.

www.jingle-iklan.-tv.blogspot.com. 14

Maret 2011

www.kompas.com. 14 Februari 2011 